\title{
La Educación Social Penitenciaria: ¿De dónde venimos y hacia dónde vamos?*
}

\section{The Prison Social Education: Wherefrom we come and towards where do we go?}

\author{
Francisco José DEL POZO SERRANO y Fanny T. AÑAÑOS-BEDRIÑANA \\ Universidad Complutense de Madrid y Universidad de Granada
}

Recibido: Marzo 2012

Aceptado: Abril 2012

\section{Resumen}

La Educación Social Penitenciaria, se abre paso como ámbito de estudio y acción con identidad y fortalezas incuestionables, no solo por su urgencia y necesidad, sino por la evolución y revolución que ha generado en el medio penitenciario español; a pesar de la pervivencia de enfoques tradicionales orientados hacia la punición y la terapia como formas de intervención en el campo socioeducativo. El trabajo analiza la evolución de la acción y estado de la cuestión en contextos de encierro y privación de libertad, estudia la praxis de los programas denominados socioeducativos y ofrece lineamientos básicos para la intervención. Al tiempo, presenta aportes en la identificación, definición y clasificación de las teorías y actuaciones en el campo y; especialmente, fundamenta un nuevo "modelo socioeducativo emergente" (MSE) de pensamiento y acción en el medio penitenciario.

Palabras clave: Educación Social, medio penitenciario, acción socioeducativa, programas de intervención, modelo socioeducativo emergente (MSE).

\begin{abstract}
The Prison Social Education, opened a way as a domain of study and action by identity and unquestionable strengths, not only for its urgency and its need, its indispensability, but for the evolution and revolution that it has generated in the prison Spanish ennvironment; in spite of the survival of traditional approaches orientated towards the punishment and the therapy like intervention forms in the social- educational field.

This paper analyzes the evolution of the action and conditions of the question in contexts of confinement and privation of freedom, it studies the practice of the programs called "social-
\end{abstract}

* Agradecimiento: Ministerio de Ciencia e Innovación, España. Plan Nacional de Investigación. Proyecto de Investigación $\mathrm{I}+\mathrm{D}+\mathrm{I}$ "mujeres reclusas drogodependientes y su reinserción social. Estudio socioeducativo y propuestas de acción”. Referencia: EDU200913408. 
educational" and it offers basic limits for the intervention. In the same times, it presents contributions in the identification, definition and classification of the theories and interventions in the field and; specially, it bases a newly "emergent social- educational model" (ESM) of thought and action in the prison environment.

Keywords: Social Education, prison environment, social-educational action, intervention programs, emergent social- educational model (ESM).

\section{La Educación Social Penitenciaria como ámbito liberador}

Permanentemente, se ha debatido si en los contextos de encierro es posible educar. Plantearse la praxis educativa o socioeducativa liberadora en un medio cerrado, punitivo y violento ¿es una utopía?, ¿es una paradoja?, ¿es una contradicción? Si consideramos la Educación como derecho fundamental y universal de las personas (y muy especialmente de las personas presas) la utopía se desdibuja configurando espacios, momentos y procesos factibles a partir de apuestas y proyectos de acciones concretas.

En esta línea, Scarfó (2002) avanza señalando la Educación como base de la identidad ciudadana: "quien no reciba o haga uso de este derecho pierde la oportunidad de pertenecer a la sociedad, a participar de manera real y constituirse en un ciudadano, que haga uso de sus derechos y cumpla con sus deberes a favor del desarrollo de la sociedad" (p.291).

Fruto de estas necesidades -y de posibilidades- nace la Resolución sobre la educación en los establecimientos penitenciarios, aprobada en el $5^{\circ}$ Congreso Mundial de la Educación (Berlín, Alemania, julio de 2007). En ella se afirma que el acceso a la educación en los establecimientos penitenciarios debería incluir temas, además de las habituales (educación básica y general para adultos, educación profesional acreditada, actividades creativas y culturales, educación física y deportes), sobre educación social porque se considera imprescindible para la recuperación- y programas de reinserción antes y después de la puesta en libertad (I.E., 2007:50). En este marco la Educación no es solamente un reto, es un derecho y un principio deontológico que debe buscar, siguiendo a Ayuso (2003), el desarrollo de la autonomía de cada persona internada a pesar de las barreras punitivas.

Por su parte, la Pedagogía Social (PS), como disciplina científica, y su brazo operativo, la Educación Social (ES), estudian e intervienen sobre distintas realidades, problemas, desafíos o retos que perviven o surgen en cada contexto. El fin, según Añaños (2010), es el de ofrecer respuestas viables que permitan el cambio, mejorar las condiciones y calidad de vida de las personas y grupos, en una permanente interrelación con el entorno en mutua interdependencia. Una teoría y praxis socioeducativa, de acuerdo al profesor Caride (2010), orientada a que los individuos, además de tener conciencia de su medio, reflexionen y actúen críticamente sobre ella con la intención de transformarla. 
Los campos o ámbitos en los que se desenvuelven la PS y la ES son sumamente amplios y diversos, se definen y redefinen en función a las características y peculiaridades de cada contexto, a las personas, al pensamiento, a la cultura, al momento histórico, etc. A su vez, los diferentes autores y corrientes, en su interior, hacen diversas clasificaciones, en espacios formales o fuera del marco escolar, según la tipología de intervención, de la población, del equipamiento, entre otros (Añaños, 2012).

En dicho panorama constatamos que las definiciones de la Pedagogía Penitenciaria (como ciencia) y Educación Social Penitenciaria (ESP) (como campo operativo y profesional) no han sido muy prolijas, pese a que nos hallamos ante una numerosa población. De acuerdo a la última publicación, en febrero de 2012, del Ministerio del Interior, Secretaría General de Instituciones Penitenciarias, se tienen registrados 71.387 presos/as, de los cuales 65.091 (92,42\%) son hombres y 5.336 $(7,58 \%)$ son mujeres (Secretaría General de Instituciones Penitenciarias, 2012). Sin embargo, estos datos no reflejan a aquellos/as que ya pasaron por esta sanción ni a la gran cantidad de afectados/as directa e indirectamente por esta situación.

La Pedagogía Social Penitenciaria, según Fermoso (2003) “Atiende a los problemas específicos de los reclusos (internos para la Administración), privados de libertad, de los menores en centros especiales y de la reinserción sociolaboral de quienes han pasado por este tipo de instituciones. Los Centros penitenciarios tienen ya en su plantilla educadores sociales especializados, y Ministerio, CCAA, Diputaciones y Ayuntamientos y algunas Congregaciones religiosas católicas sostienen pisos o pequeñas células de ex presos, para ayudarles a reinsertarse social y laboralmente" (p.81).

Así, la Educación Social Penitenciaria (ESP) supone "la acción socioeducativa de la Administración Penitenciaria y, fundamentalmente, de entidades públicas y privadas, durante el tiempo de internamiento penitenciario, semilibertad y libertad definitiva; mediante programas y acciones individualizados o grupales desarrollados por educadores/as (especialmente no penitenciarios), favoreciendo la recuperación, reeducación, reinserción sociolaboral y socialización para la reincorporación a su comunidad" (Del Pozo y Mavrou, 2010: 236).

Por otro lado, la ESP objeto de nuestro trabajo, podemos situarla en su clasificación, como un ámbito dentro de la Educación Social Especializada (ESE). Esta vertiente plantea además escenarios de actuación donde se pueden relacionar variadas y complejas situaciones asociadas a multiproblemáticas sociales específicas de gran vulnerabilidad, riesgo, dificultad o conflicto social: delincuencia, drogodependencia, abandono, violencia, internamiento, etc. Desde esta perspectiva, uno de los principales objetivos de la ESE es el de alcanzar mayores progresos de las personas y colectivos en su sociabilidad, sin perder las características esenciales de su propia personalidad y sus potencialidades. En definitiva que "las personas con las que se actúa deseen y puedan convivir con los demás y, de esta forma, desarrollen y desplieguen su propia identidad" (Pérez, 2005:15). 
A los fines expuestos de la ESP cabe añadir una dimensión más que debería plantearse como irrenunciable en los procesos penitenciarios del tratamiento (intervención-acción): la Educación para la Libertad. Esta premisa, nos posiciona en el modelo socioeducativo que introduce "la libertad y la liberación" -como destino de aquellos fundamentos, metodologías o conjunto de medidas desarrolladas desde la ESP dirigida a cualquier contexto del medio penitenciario.

Adentrándonos en las claves analíticas de los procesos socioeducativos distinguimos que existen, entre otros, dos aspectos emergentes del propio proceso liberador: la "liberación de la coacción y la liberación de la ignorancia" (Mayor, 2000:443). Estas realidades coercitivas ${ }^{1}$ y culturales $^{2}$, particularmente significativas en escenarios de encierro, de internamiento o penitenciarios, encuentran por la ESE la dinamización de las condiciones que permiten alcanzar una mayor madurez social desde una intervención-acción a través de estrategias socioeducativas (Ortega, 1999; Franch y Martinell, 1994).

También, la actuación de la ESE como Educación para la Libertad en el ámbito penitenciario refuerza y expande su dimensión comunitaria (Del Pozo, 2008a; Morata, Muro y Palasí, 2011) entendiendo que es irrenunciable la consideración de que cualquier persona privada de libertad continúa formando parte de la comunidad. Al mismo tiempo, debemos entender la ESE como campo que desarrolla las funciones preventivas comunitarias, de un lado, en la reducción de la comisión delictiva; y de otro, generando nuevas propuestas a partir de los elementos y acciones de socialización y prevención de la reincidencia.

A la luz de estas primeras líneas, se justifica plenamente el abordar la temática educativa y penitenciaria con detenimiento y exclusividad. En el presente trabajo pretendemos no solo adentrarnos en la literatura científica correspondiente, sino analizar críticamente la evolución del estado de la cuestión y muy especialmente algunas realidades escasamente tratadas para la práctica socioeducativa, así como nos atrevemos a proponer nuevas formas de concepción y actuación en este medio.

\section{La Educación Social Penitenciaria de ayer y de hoy: Evolución de los procesos de intervención}

Tradicionalmente la intervención como Tratamiento Penitenciario ${ }^{3}$ ha estado fundamentada, entre otros, por la Criminología, la Psicopatología y la Sociología. Los

${ }^{1}$ Realidades coercitivas: Imposiciones derivadas de las instituciones punitivas, medidas de seguridad o normas disciplinarias.

${ }^{2}$ Realidades culturales: Carencias a nivel educativo reglado, modelos familiares inseguros y/o negligentes o ínfima formación profesional, etc.

3 Intervención tratamental/tratamiento penitenciario: término empleado en el lenguaje penitenciario para referirse a los procesos de intervención-acción en la población penitenciaria. Es definido o aceptado en los equipos técnicos para su desarrollo en programas/proyectos. Pueden ser individuales o de grupos específicos. 
procesos educativos-reeducativos en el ámbito penitenciario han sido abordados mayoritariamente con estos enfoques, sin que hubiera una especialización de la Pedagogía y Educación Social; consecuentemente en la configuración de éstas se han recibido, además de las propias, influencias de dichas perspectivas.

El fenómeno de la delincuencia y la acción social, así como las problemáticas derivadas de éstas, han tenido un abordaje y asentamiento teórico a partir de los aportes de García y Sancha (1985) y Yela (2004); quienes dieron lugar al surgimiento de modelos, programas y acciones que podríamos categorizar en dos grandes teorías: psicopatológicas y sociológicas. Por nuestra parte, a partir de la presentación general de las mismas, haremos hincapié en el desarrollo de las teorías pedagógicas/socioeducativas y, más adelante, propondremos una nueva visión.

\section{* Teorías psicopatológicas:}

Justifican e interpretan el acto delictivo desde factores individualizados de corte biológico o psicopatológico. Han sido muy relevantes en la historia de la delincuencia y en el tratamiento penitenciario a tal punto que incluso hasta hoy se mantiene la nomenclatura en la intervención en prisiones. Algunos representantes de estas corrientes podrían ser Eysenck y Eysenck (1971), Freud (1906), etc. Desde la rama de la psicología social, más próxima a explicaciones relacionadas con las influencias, factores y condiciones sociales, Glaser (1984) o Vygotski (1978), aportan otros enfoques que tienen en cuenta no sólo factores individualistas de la personalidad.

\section{*Teorías sociológicas:}

Implican factores más estructurales y multidimensionales. Estas teorías fundamentan que los sistemas y las relaciones sociales, educativas, familiares o culturales tienen componentes que influyen o determinan la etiología delictiva. Entre otros, podemos plantear: Teoría de la desigualdad de oportunidades (Cloward y Ohlin, 1960), desviación social (Wilkins, 1965), el etiquetado o labelling (Lemert, 1972), criminología crítica (Taylor, Walton, Young, 2000).

\section{*Teorías socioeducativas:}

Según el profesor Melendro (2010), a lo largo del pasado siglo, se han ido sucediendo modelos y perspectivas que han enriquecido y mejorado de forma destacable los métodos de intervención socioeducativa con poblaciones en desventaja social. Los planteamientos conductistas, los enfoques dinámicos, el constructivismo, la pedagogía de la vida cotidiana, la pedagogía popular ${ }^{4}$, la terapia familiar sistémica, el modelo de competencias, la terapia centrada en el cliente, entre otros, han abordado de forma sucesiva, en ámbitos a

4 Pedagogía popular: fenómeno sociocultural y concepción de educación desarrollada fundamentalmente en América Latina. Se trata de multitud de prácticas educativas que encierran una intencionalidad transformadora y se sostiene en la pedagogía crítica y creadora. Busca construir relaciones equitativas, justas, respetuosas de la diversidad y de la igualdad de derechos de las personas. Son representantes de esta corriente Paulo Freire, Carlos Rodríguez Brandao, Óscar Jara, Juan E. García Huidoboro, etc. 
veces diferenciados y en ocasiones compartidos, la difícil tarea de actuar con personas que tienen mayores dificultades para insertarse socialmente.

También ha estado vigente la discusión sobre el enfoque de los programas, es decir si deberían estar dirigidos hacia la reducción de los llamados factores de riesgo o, por el contrario, centrados en los factores de protección. Aún perviven programas donde lo prioritario es la disminución o reducción de los factores de riesgo, sin embargo, hoy, se tiende más hacia una visión personalista de la reeducación, donde se defiende, fundamentalmente, que es la persona la que cambia -si así lo quiere-, asimismo demarca los límites de dicho cambio -hasta dónde-. Así, se han ido poniendo en marcha programas en torno al desarrollo de las fortalezas de la persona, también denominados factores de protección. En este enfoque se ha apostado por la resiliencia personal y social. Los programas actuales procuran enfocar ambos aspectos.

La Pedagogía/Educación Social, en el medio penitenciario, a pesar de sus grandes avances, está aún relegada a un segundo plano, donde con frecuencia no se utilizan sus fundamentos, metodologías y acciones propias (Del Pozo, 2008b). De hecho, los mismos educadores, han mantenido una función de gestión penitenciaria, más que de acción socioeducativa en sí. Esta situación empieza a modificarse a partir de la Circular de la Dirección General de Instituciones Penitenciarias del año 2006, el traspaso de las competencias referidas a la programación y seguimiento del conjunto de actividades educativas, deportivas, ocupacionales y culturales a la Subdirección General de Tratamiento y Gestión Penitenciaria, que con anterioridad correspondían al Organismo Autónomo de Trabajo y Prestaciones Penitenciarias, así como la creación en la citada Subdirección General de una nueva Área de Diseño, Seguimiento y Evaluación de Programas Específicos de Tratamiento.

Por otro lado, se asume con más fuerza el mandato constitucional y las distintas leyes y normas que toman como principio fundamental la educación y reeducación en los procesos de privación de libertad. A la vez, se visibiliza la necesidad de propuestas socioeducativas acordes que dan lugar a una nueva concepción del tratamiento, así como se enfatiza la importancia de los equipos multidisciplinares y la aplicación de técnicas y métodos de forma individual (PEI) como de grupo (PEG), donde la dimensión crítica, autónoma y emancipadora de la persona se erige imprescindible (Añaños, 2012).

Esta concepción pone en relieve la trascendencia de los Programas Socioeducativos -de tratamiento para Instituciones Penitenciarias (II.PP.)- como estrategias durante el internamiento para su transformación y mejora. A estos hechos se añade la presencia paulatina e incorporación laboral de educadores/as sociales titulados/as o habilitados/as, monitores/as socioculturales, etc.

Según el Reglamento Penitenciario, las actuaciones de II.PP. para favorecer la inserción de las personas privadas de libertad se concretan, entre otras, en la enseñanza reglada y no reglada, formación ocupacional, trabajo y desarrollo cultural y social, atención social que se presta a los internos, a los/las liberados/as condicionales y a las familias de unos y otros. 


\section{Los Programas Socioeducativos -de Tratamiento- en contextos penitenciarios}

Sistematizar y abordar las características, tipologías, enfoques, metodologías, etc. que definen la panorámica actual de los escenarios de intervención-actuación socioeducativa en prisiones es una necesidad actual y urgente para una praxis fundamentada y coherente.

Los programas implementados en este ámbito, tal como se ha señalado en las teorías que fundamentaron el campo se han basado en corrientes tradicionalmente punitivas $\mathrm{y}$, progresivamente éstas han ido evolucionando hacia otras perspectivas. Veamos algunas concreciones.

Dos modelos han sido básicos para cimentar la naturaleza del proceso resocializador (De la Cuesta, 1993): El modelo funcionalista asentado en la suplencia de las carencias producidas en el proceso de socialización del individuo; y el de corrección, centrado en las ineptitudes para el control del comportamiento. Con otras denominaciones, se consideran a los primeros como Modelos para la Moralidad (regeneración de valores morales dominantes) con influencias de manipulación y aceptación acrítica de los sistemas vigentes y; a los segundos en la línea de los Modelos para la legalidad (adecuación del comportamiento a las normas, derechos y deberes jurídicamente establecidos).

La intervención penitenciaria, de acuerdo a Garrido y Gómez (1995), se ha centrado tradicionalmente en modelos científicos-tecnológicos (enmarcada en los enfoques médicos de tradición conductual, donde se busca el alineamiento del sujeto, y presentes en la pedagogía positivista). La búsqueda de conductas, desde el tratamiento clásico en las prisiones, ha buscado la reproducción de esquemas sociales desde una educación que no ha tenido en cuenta variables contextuales o socioculturales).

Los programas correctivos han sido los más recurrentes en la aplicación tratamental en las prisiones. Desde esta perspectiva la intervención de los programas en prisiones han estado centrados en modelos conductuales de refuerzos o castigos (Morris y Braukmann, 1987; Redondo, 1995). Podríamos resumir los modelos en cuatro grandes grupos: a) Modelo psicológico y psicoanalítico (Freud, 1906; Bowlby, 1995), b) Modelo biológico-conductual (Eysenck y Eysenck, 1971, etc.) c) Modelo factoralista (Hathaway y Monachesi, 1953). La evaluación de estos programas correctivos (Milan y Evans, 1987) gira sobre la efectividad de los mismos, con mediciones cuantitativas antes y después de la implementación.

En los modelos que denominamos humanistas encontramos algunos que podremos clasificar en otras grandes tipologías (Yela, 2004).

a) Modelos generales de prevención (Bloom, 1998).

b) Modelos basados en la competencia social (Andrews y Bonta, 2006).

c) Modelos en competencia emocional (Goleman, 1996).

d) Modelo sociocutural (Bandura, 1997).

e) Modelos basados en la necesidades o capacidades (Orte, 2008). 
Las diferentes concepciones y terminologías aplicadas a la Educación en el ámbito penitenciario han ido evolucionando y se han ido conformando modelos pedagógicos de mayor enfoque positivista: como la pedagogía de la delincuencia, pedagogía correccional, pedagogía de la inadaptación social u otras de corte sociocrítico como la pedagogía del riesgo o la pedagogía de la reeducación y reinserción social.

Finalmente, hoy, aterrizamos en una Pedagogía posicionada en principios paradigmáticos que toman visiones humanistas y metodológicas, pero que, a su vez, se erigen liberadores. El análisis de las propuestas nos visibiliza distintas perspectivas, a las que hemos clasificado, caracterizado y denominado, en un intento de organizar y categorizar los enfoques de actuación, así tenemos:

Modelo participativo (Ayuso, 2000), en el que el tratamiento penitenciario debe contener en la acción socioeducativa la participación de toda la comunidad penitenciaria (principalmente de las personas internadas) en el conjunto del proceso y la voluntariedad de la población reclusa para asumir los programas tratamentales.

Modelo para la autonomía, defendidos desde los programas educativos individualizados y grupales por el profesor Pantoja (2010).

Modelos para el empoderamiento y/o de género. Estos se podrían plantear desde un doble enfoque: atendiendo a la superación sociocultural y estructural establecida por la criminalización efectuada contra las mujeres delincuentes (Juliano, 2010; Almeda, 2010) y las medidas para la Igualdad que desarrollen los procesos de equidad entre hombres y mujeres en el medio penitenciario (Yagüe, 2008, 2010). También en estos modelos la acción penitenciaria se plantea a partir de los factores protectores, de las capacidades y de las potencialidades de las personas privadas de libertad, especialmente desde la voluntariedad y superación de las barreras personales, sociales o estructurales que generen la dignificación de los/las reclusos/as, especialmente de quienes sufren mayores situaciones de violencia, vulnerabilidad o deterioro (Añaños, 2010, 2012; Del Pozo, 2010). Por otro lado, los principios y finalidades de las acciones irán vinculadas a los procesos de empoderamiento, a la consecución de los derechos humanos, a la igualdad, a la justicia y a la paz, porque conducen ineludiblemente a la conquista de una ciudadanía responsable, participativa y democrática (Martín, 2010).

Modelos del conocimiento de las personas y de las acciones pedagógicas, en los que incide el profesor Sáez (2010), donde el deseo y el disfrute de lo que se haga, así como el consenso colectivo del trabajo y la relación educativa entre el/la preso/a y el/la educador/a emerge con fuerza. Del mismo modo el hecho de integrarse y sumergirse dentro del mismo contexto se hace imprescindible (Ibídem; Pantoja y Añaños, 2010), porque si tenemos como base las diversas realidades puede generarse, en palabras de la profesora Núñez (2010), un "microcosmos carcelario" a favor del encuentro de objetos diversos y universos múltiples: escapatorias y refugios culturales (p.74), pero sin olvidar el respeto de su personalidad e identidad (Pérez, 2005).

Modelos para la liberación, defendidos por el profesor Caride (2010), se contempla que la inserción renueva la intervención penitenciaria en la dimensión profesional y estructural, mediante el desafío de convertir los espacios y los conceptos penitenciarios 
en posibilidades de libertad. El acompañamiento educativo busca la liberación de la institución que debe superar el miedo a la "seguridad como principal objetivo" y superar "el miedo" de una actuación; así, también, el acompañamiento del personal técnico basado en las decisiones de las propias personas internadas para la construcción de sus propios itinerarios de inserción y reincorporación social. Así mismo, se afianza la idea de que la ESP "ha de ser una práctica de y hacia la libertad. Sintamos la necesidad de proyectar en la Educación Social como revolucionaria para educar procurando que las personas pierdan el miedo a la libertad (en el sentido positivo de realización de su propia personalidad individual) pero también de encuentro, diálogo y convivencia con los demás" (Ibídem: 61).

En la Tabla 1 se resume en una nueva clasificación modelos, corrientes y denominaciones, desde una perspectiva educativa, sobre los principios teóricos $\mathrm{y}$ prácticas en el medio penitenciario.

Tabla 1: Modelos y programas penitenciarios.

\begin{tabular}{|c|c|c|}
\hline $\begin{array}{l}\text { Modelos científico- } \\
\text { Tecnológicos }\end{array}$ & Modelos humanistas & $\begin{array}{l}\text { Modelos } \\
\text { socioeducativos/liberadores }\end{array}$ \\
\hline $\begin{array}{l}\text { Psicopatológicos, } \\
\text { positivistas. } \\
\text { (Freud, 1906; Bowlby, } \\
\text { 1995; Hathaway y } \\
\text { Monachesi, 1953; Eysenck y } \\
\text { Eysenck, 1971; Milan y } \\
\text { Evans, 1987; Hamm y } \\
\text { Scrinck, 1989; Morris y } \\
\text { Braukmann, 1987; Garrido y } \\
\text { Gómez, 1995, 1996; } \\
\text { Redondo, 1995). }\end{array}$ & $\begin{array}{l}\text { Epistemológicos, } \\
\text { críticos, hermenéuticos. } \\
\text { (Cloward y Ohlin, 1960, } \\
\text { Goleman, 1996, Bloom, 1998; } \\
\text { Bandura, 1997; Andrews, D. A., } \\
\text { y Bonta, J, 2006; Orte, 2008, } \\
\text { etc.). }\end{array}$ & $\begin{array}{l}\text { Empoderamiento, transformador, } \\
\text { emancipador, democrático, } \\
\text { participativo, de género, } \\
\text { conocimiento de la realidad. } \\
\text { (Ayuso, 2000; Añaños, 2010, 2012; } \\
\text { Del Pozo, 2010; Pérez, 2005; Sáez, } \\
\text { 2010; Martín Solbes, 2010; Pantoja, } \\
\text { 2010; Pantoja y Añaños, 2010; } \\
\text { Núñez, 2010; Caride, 2010, Yagüe, } \\
\text { 2008, 2010; Almeda, 2010; Juliano, } \\
\text { 2010). }\end{array}$ \\
\hline $\begin{array}{l}\text { Programas funciona-listas } \\
\text { correctivos, basados en } \\
\text { patologías, déficits } \\
\text { cognitivos y desviaciones. El } \\
\text { enfoque preferentemente es } \\
\text { punitivo, sancionador y } \\
\text { conductual. }\end{array}$ & $\begin{array}{l}\text { Programas de intervención } \\
\text { basados en necesidades, } \\
\text { especificidades, capacidades y } \\
\text { estructuras sociopolíticas. }\end{array}$ & $\begin{array}{l}\text { Programas basados en procesos } \\
\text { transformadores de mejora, a partir } \\
\text { de su concienciación y realidad. } \\
\text { Tiene en cuenta la perspectiva de } \\
\text { género y sus potencialidades. } \\
\text { Implica procesos colaborativos, } \\
\text { multidisciplinares y democráticos. }\end{array}$ \\
\hline $\begin{array}{l}\text { Pedagogía de la } \\
\text { Delincuencia } \\
\text { Pedagogía de la } \\
\text { Inadaptación } \\
\text { Pedagogía Correccional }\end{array}$ & $\begin{array}{l}\text { Pedagogía Penitenciaria } \\
\text { Pedagogía de la Reinserción } \\
\text { Pedagogía de la Rehabilitación. }\end{array}$ & $\begin{array}{l}\text { Pedagogía de la Liberación } \\
\text { Pedagogía del Empoderamiento } \\
\text { Pedagogía Integral }\end{array}$ \\
\hline $\begin{array}{l}\text { Ej. Programas correctivos } \\
\text { de "aislamiento", etc. }\end{array}$ & $\begin{array}{l}\text { Ej. Programas terapéuticos } \\
\text { conductuales, ocupacionales, } \\
\text { etc. }\end{array}$ & $\begin{array}{l}\text { Ej. Programas para la Igualdad } \\
\text { entre hombres y mujeres en el } \\
\text { ámbito penitenciario, módulos de } \\
\text { respeto, etc. }\end{array}$ \\
\hline
\end{tabular}




\section{Configurando el "Modelo Socioeducativo Emergente" (MSE)}

A partir de nuestras concepciones y experiencias, además de los enfoques/modelos analizados, planteamos uno nuevo que hemos denominado "Modelo Socioeducativo Emergente" (MSE) de acción en el medio penitenciario que, podría caracterizarse principalmente por los siguientes lineamientos:

- Algunos fundamentos teóricos: Sus bases teóricas, científicas, metodológicas y prácticas beben de la Pedagogía y Educación Social, especialmente autónomas y liberadoras para el cambio. Interactúa con otros conocimientos que intervienen en el medio penitenciario, por ejemplo el trabajo social, la psicología social, la sociología, la criminología, el derecho, etc. Éstas, a lo largo de la historia, han sido las encargadas preferentes de la acción y cuentan con un legado importante, así mismo, hoy, mantienen su vigencia y hay que trabajar coordinada y cooperativamente.

Desarrolla, también, el enfoque humanista y crítico de las dimensiones epistemológicas, categorías, estructuras sociales y modelos metodológicos asociados a la propia institución y realidades penitenciarias, a partir de su conocimiento, deseo y disponibilidad al cambio. Se privilegia la confianza -en la persona en sí, en las acciones a realizar y en las relaciones- y la participación voluntaria y responsable.

Es coherente a las múltiples situaciones de las personas privadas de libertad en el medio penitenciario, entre otros, a su vida en prisión, a su condena, al género, a los programas en los que participa, al entorno personal, familiar y relacional que influye en sus procesos emocionales y configuran redes de apoyo que refuerzan o debilitan la preparación para la libertad, la reeducación y la reinserción.

Enfatiza la necesidad de la deconstrucción sociocultural de las estructuras, procesos, imaginarios (representaciones sociales) y situaciones de desigualdad, de violencia, de vulnerabilidad, de riesgo, de conflicto, de los efectos de la prisionalización ${ }^{5}$, de marginación y/o de exclusión; o de aquello que suponga una barrera o dificultad para la socialización e interrelación positiva con su entorno y la sociedad, para la convivencia pacífica y para la optimización o mejora de las condiciones de vida y/o de la calidad de vida del colectivo. A la par, construir integralmente los elementos orientados a buscar el cambio y la mejora real.

- Metodologías: Ofrece métodos y actividades que buscan la participación activa de las personas internadas, buscando la integralidad de las acciones, la democratización de las opciones y voluntades. Se basa en la configuración de programas pertinentes desde un conocimiento profundo de las distintas realidades (personales, familiares, sociales, penitenciarias, etc.); del análisis,

5 Prisionalización: Adaptación a la vida penitenciaria y “aculturación” con unas consecuencias en el ser humano en todos los campos (biofísico, educativo, social, familiar, ambiental, etc.). 
priorización y evaluación exhaustiva de las necesidades/potencialidades y capacidades tanto individuales como grupales; de la cercanía, disfrute, identificación y viabilidad de la propuesta, etc.

- Fines: Busca, entre otros, la autonomía, la autogestión, el afrontamiento crítico y realista de su vida y de su proceso progresivo de cambio, el empoderamiento personal, social, familiar de la inserción y participación prosocial activa en su comunidad.

- Temporalización: Concebida a lo largo de los distintos períodos penitenciarios, y especialmente, en aquellas situaciones, fenómenos o momentos de mayor riesgo o conflicto (dependiendo del caso: ingreso, clasificaciones, primeros permisos, tercer grado, libertad condicional), donde pueden incluirse el hecho de "recaer, reincidir o equivocarse"; entendiéndose y abordándose éstos en el marco de la actuación y los programas de acción dentro de los propios estadíos y procesos de transformación.

Con estas perspectivas no encontramos ningún programa vigente. El programa que nos podría servir de ejemplo se encuentra en fase de diseño, bajo el amparo del Proyecto de Investigación I+D+I, del Plan Nacional de Investigación, "Mujeres reclusas drogodependientes y su reinserción social. Estudio socioeducativo y propuestas de acción”. Referencia: EDU2009-13408. Éste, a pesar de que no se haya aplicado, nos permite reflexionar, cuestionar y continuar investigando sobre el modelo a partir de las teorías y resultados empíricos que se van produciendo.

Este posicionamiento, supera los modelos tradicionales carcelarios de actuación, le da un giro, desde visiones y aspectos que amplían y enriquecen la concepción legislada sobre la "Re-educación" en las prisiones, planteadas en la Carta Magna -Art. 25.2-. También, refuerza en la necesidad de un trabajo cooperativo y en equipo, porque la complementación de las áreas y profesionales implicados se erigen importantes para una acción ecológica, grupal e individualmente; todo ello teniendo como eje vertebrador y transversal de la Educación Social Penitenciaria.

\section{La Praxis socioeducativa en el Medio Penitenciario: Programas, acciones y ámbitos de actuación}

En el apartado ofrecemos una clasificación que permite incluir espacios o contextos que no han sido tradicionalmente considerados por parte II.PP. Pero, existen "programas de tratamiento" desarrollados en y desde la Administración Penitenciaria que pueden tener enfoques, contenidos o áreas con una perspectiva socioeducativa, o en contra no contemplarlos, incluso, hay programas que aparecen denominados como "socioeducativos" que tienen una vocación únicamente asistencialista.

Así, Gil (2010) plantea, dos cuestiones para la intervención en prisión. Una nace de la necesidad de que las acciones pedagógicas sean desarrolladas por personal profesional, aunque participen en programas de voluntariado o de $\mathrm{ONG}^{\prime}$ 's; y otra, que 
la vida en prisión debe estar llena de actividad, y no ser un espacio vacío, carente de un verdadero proceso de reinserción y reeducación. Por tanto, es prioritario clarificar y clasificar los programas socioeducativos y el rol profesional, considerando algunos criterios como:

*Que el diseño, fundamentos y elementos se basen en la Pedagogía/Educación Social como disciplina y acción vertebradora.

*Que tengan una amplia implementación en el medio penitenciario o que se considere un programa de calidad o eficacia en los resultados.

*Que los agentes que los diseñan y/o desarrollan sean profesionales de la acción socioeducativa.

*Que busquen la mejora de las competencias prosociales a través de los procesos educativos individuales o grupales.

*Que contemplen las situaciones y realidades del grupo específico a los que se dirige, a partir de los cuales se genere una concienciación crítica orientada al cambio.

*Etc.

La modalidad de programas es amplia e inciden en la población general o por colectivos específicos. Así podemos distinguir: "programas familiares" llevados fundamentalmente por trabajadores sociales, no obstante conllevan muchas acciones educativas (Yagüe, 2011) y en los últimos años se abre paso para el desarrollo educativo. Los programas en el que nos detendremos son: "habilidades sociales" y "participación sociocultural".

\section{a) Programas de Habilidades sociales}

Con frecuencia forman parte de otros programas, pero existen, también, exclusivos en el tema. Son relevantes en las situaciones de marginación y exclusión social. Así, hay programas llamados en Riesgo de exclusión social, dirigidos a mujeres (prevención de la violencia de género -"Ser mujer.es"-, acciones para la igualdad entre hombres y mujeres en el ámbito penitenciario -II.PP.-, SURT, etc.); a jóvenes -18 a 21 años(ADHEX, 2011- o programas en los módulos de jóvenes) y; a otros colectivos de atención específica (Mayores, extranjeros, discapacitados, drogodependientes -Añaños, 2010-, etc.). También hay programas para personas con especiales problemas de conducta, multireincidencias, sanciones, etc. denominados de Conflicto social. Un grupo de programas de gran relevancia educativa son los señalados como Socioeducativos, en él destacamos los "módulos de respeto"; las "unidades

${ }^{6}$ Módulo de respeto: Creada en 2001 en el C.P. Mansillas de las Mulas (León), hoy se encuentra en casi la totalidad de los centros (II.PP., 2011). Se trabaja mediante metodologías participativas y estrategias que inciden en estilos de vida orientados a la búsqueda del cuidado personal y ambiental, el respeto a la alteridad y la construcción positiva de la interrelación. 
dependientes", en las que resaltamos las de mujeres con hijos/as ("Romper Cadenas", abierta hasta el 2011 en Granada, -Del Pozo y Mavrou, 2010-) y; los "centros de inserción social" (CIS).

\section{b) Programas socioeducativos para la participación sociocultural}

Estas se pueden agrupar en ocupacionales y culturales. Los Ocupacionales se orientan a la formación laboral, aunque muchos pueden responder al quehacer más o menos útil del tiempo mediante cursos como electricidad, carpintería, manualidades, etc. Otros participan de la vocación transformadora y liberadora, como los programas y experiencias teatrales ("Compañía Yeses"7), siendo éstos una herramienta de cambio educativo-formativo de gran aceptación y se configuran en estrategias de empoderamiento (Del Pozo, 2011). En los programas Culturales destaca "animación de la lectura", "actividades de biblioteca", "actividades musicales y audiovisuales"; formación de grupos de "rock", "flamenco" (C.P. Albolote, en Granada -Añaños y Del Pozo, 2010-), "vídeo", "vídeo-fórum", "poesía", edición de revistas ("La voz de Mako"s), etc.

En la Tabla 2 abordamos una identificación y categorización de las actuaciones desarrolladas por los/as educadores/as sociales (sean titulados/as, habilitados/as o no) en los diferentes recursos ${ }^{9}$ (cerrados, semiabiertos y abiertos), incorporando las tipologías de centros y las clasificaciones penitenciarias posibles en cada medio, interrelacionando, a su vez, con la pluralidad de escenarios existentes y algunos de los programas socioeducativos implementados. Se completa con la identificación de los perfiles profesionales o tipos de agentes más comunes en cada bloque.

7 Compañía Yeses: Creada en 1995 y ubicada en el C.P. Madrid I. Es el proyecto teatral más importante del ámbito penitenciario en España y posiblemente en Europa. Goza de prestigiosos premios y reconocimiento profesional. ( www.teatroyeses.com )

${ }^{8}$ La "Voz de Mako": Editada en C.P. Albolote, Granada, para la lectura de los internos y para la comunidad. Se abordan problemáticas de salud, de experiencias de vida y penitenciarias, cuestiones sociales globales, literatura, etc.

${ }^{9}$ Esta categorización no parte totalmente de las clasificaciones establecidas por Instituciones Penitenciarias (II.PP.), puesto que en los dispositivos contemplados, en nuestro trabajo, como "medio de semilibertad", se ubican dentro del Medio Abierto de la Administración, Ministerio del Interior, gestionados por la Subdirección General de Medio Abierto. 
Tabla 2. Especialización de los/las Educadores/as Sociales en escenarios, medios y programas penitenciarios

\begin{tabular}{|c|c|c|c|}
\hline $\begin{array}{c}\text { Medio } \\
\text { y/clasificación } \\
\text { penitenciaria }\end{array}$ & $\begin{array}{c}\text { Escenarios y } \\
\text { Población }\end{array}$ & $\begin{array}{c}\text { Programas } \\
\text { predominantemente de } \\
\text { enfoque socioeducativo }\end{array}$ & Agentes \\
\hline $\begin{array}{l}\text { Cerrado } \\
\text { (C.P. Ordinario: } \\
\text { Situación } \\
\text { preventiva, } \\
\text { primer y } \\
\text { segundo grado) }\end{array}$ & $\begin{array}{l}\text { Módulos } \\
\text { ordinarios: } \\
\text { (hombres, } \\
\text { mujeres, madres } \\
\text { o mixtos) }\end{array}$ & $\begin{array}{l}\text { - Programas individualizados } \\
\text { de tratamiento (PIT). } \\
\text { - Programas familiares, } \\
\text { formativo-laborales, de } \\
\text { habilidades sociales, } \\
\text { resolución de conflictos, } \\
\text { preparación para la libertad, } \\
\text { prevención de } \\
\text { drogodependencias, } \\
\text { educación infantil -en el caso } \\
\text { de los maternales-, etc. }\end{array}$ & $\begin{array}{l}\text { - Educadores/as del } \\
\text { cuerpo técnico de I.I.P.P. } \\
\text { - Educadores/as como } \\
\text { voluntarios o } \\
\text { profesionales de } \\
\text { entidades sin ánimo de } \\
\text { lucro o entidades } \\
\text { externas no } \\
\text { penitenciarias. }\end{array}$ \\
\hline $\begin{array}{l}\text { Cerrado } \\
\text { (C.P. Ordinario: } \\
\text { Situación } \\
\text { preventiva, } \\
\text { primer y } \\
\text { segundo grado) }\end{array}$ & $\begin{array}{l}\text { Módulos } \\
\text { socioculturales: } \\
\text { (Mixtos) }\end{array}$ & $\begin{array}{l}\text { - Programas socioculturales: } \\
\text { (arte, música, teatro, pintura, } \\
\text { biblioteca, lectura, etc.). } \\
\text { - Programas ocupacionales: } \\
\text { formación en talleres } \\
\text { productivos o industriales. } \\
\text { - Programas deportivos: } \\
\text { Educación deportiva, física y } \\
\text { salud. }\end{array}$ & $\begin{array}{l}\text { - Monitores/as o } \\
\text { educadores/as } \\
\text { ocupacionales, } \\
\text { socioculturales o } \\
\text { deportivos. }\end{array}$ \\
\hline $\begin{array}{l}\text { Cerrado } \\
\text { (C.P. Ordinario: } \\
\text { Situación } \\
\text { preventiva, } \\
\text { primer y } \\
\text { segundo grado, } \\
\text { con una mayor } \\
\text { presencia de } \\
\text { segundo grado) }\end{array}$ & $\begin{array}{l}\text { Módulos de } \\
\text { respeto: } \\
\text { (Habitualmente } \\
\text { son de mujeres o } \\
\text { de hombres } \\
\text { exclusivamente) }\end{array}$ & $\begin{array}{l}\text { - Programas de convivencia } \\
\text { (habilidades sociales y } \\
\text { personales, autonomía y } \\
\text { liderazgo). } \\
\text { - Programas de } \\
\text { interculturalidad. } \\
\text { - Programas de valores. }\end{array}$ & $\begin{array}{l}\text { - Educadores/as del } \\
\text { cuerpo técnico de I.I.P.P. } \\
\text { - Educadores/as como } \\
\text { voluntarios o } \\
\text { profesionales de } \\
\text { entidades sin ánimo de } \\
\text { lucro o entidades } \\
\text { externas no } \\
\text { penitenciarias. } \\
\text { - Propios agentes } \\
\text { educadores internos/as } \\
\text { del módulo. }\end{array}$ \\
\hline
\end{tabular}




\begin{tabular}{|c|c|c|c|}
\hline $\begin{array}{l}\text { Abierto } \\
\text { (Módulo o } \\
\text { sección abierta } \\
\text { dentro de un } \\
\text { centro ordinario: } \\
\text { Clasificación en } \\
\text { Tercer grado) }\end{array}$ & $\begin{array}{l}\text { Sección } \\
\text { Abierta: } \\
\text { (Habitualmente } \\
\text { mixto, aunque } \\
\text { existen } \\
\text { únicamente de } \\
\text { mujeres y de } \\
\text { hombres } \\
\text { respectivamente) }\end{array}$ & $\begin{array}{l}\text { - Programas de preparación } \\
\text { para la libertad. } \\
\text { - Programas formativo- } \\
\text { laborales. }\end{array}$ & $\begin{array}{l}\text { - Educadores/as del } \\
\text { cuerpo técnico de I.I.P.P. } \\
\text { - Educadores/as como } \\
\text { voluntarios o } \\
\text { profesionales de } \\
\text { entidades sin ánimo de } \\
\text { lucro o entidades } \\
\text { externas no } \\
\text { penitenciarias. } \\
\text { - Educadores/as de redes } \\
\text { externas. }\end{array}$ \\
\hline $\begin{array}{l}\text { Semiabierto } \\
\text { (Tercer grado) }\end{array}$ & $\begin{array}{l}\text { Unidades } \\
\text { externas de } \\
\text { madres }\end{array}$ & $\begin{array}{l}\text { - Programas de educación } \\
\text { familiar, infantil, formativo- } \\
\text { laboral y habilidades } \\
\text { sociales. }\end{array}$ & $\begin{array}{l}\text { - Educadores/as del } \\
\text { cuerpo técnico de I.I.P.P. } \\
\text { - Educadores/as como } \\
\text { voluntarios o } \\
\text { profesionales de } \\
\text { entidades sin ánimo de } \\
\text { lucro o entidades } \\
\text { externas no } \\
\text { penitenciarias. } \\
\text { - Educador/a infantil. }\end{array}$ \\
\hline $\begin{array}{l}\text { Semiabierto } \\
\text { (Tercer grado) }\end{array}$ & $\begin{array}{l}\text { Centro de } \\
\text { Inserción Social } \\
\text { (CIS) }\end{array}$ & $\begin{array}{l}\text { - Programas individualizados } \\
\text { de tratamiento (PIT). } \\
\text { - Programas familiares, } \\
\text { formativo-laborales, de } \\
\text { habilidades sociales, } \\
\text { resolución de conflictos, } \\
\text { preparación para la libertad, } \\
\text { prevención de } \\
\text { drogodependencias, etc. }\end{array}$ & $\begin{array}{l}\text { - Educadores/as del } \\
\text { cuerpo técnico de I.I.P.P. } \\
\text { - Educadores/as como } \\
\text { voluntarios o } \\
\text { profesionales de } \\
\text { entidades sin ánimo de } \\
\text { lucro o entidades } \\
\text { externas no } \\
\text { penitenciarias. } \\
\text { - Educadores/as de redes } \\
\text { externas. }\end{array}$ \\
\hline $\begin{array}{l}\text { Semiabierto } \\
\text { (Art. 170) }\end{array}$ & $\begin{array}{l}\text { Comunidades } \\
\text { terapéuticas }\end{array}$ & $\begin{array}{l}\text { - Programas de prevención } \\
\text { de drogodependencias. } \\
\text { - Programas de habilidades } \\
\text { sociales. }\end{array}$ & $\begin{array}{l}\text { Educadores/as como } \\
\text { voluntarios o } \\
\text { profesionales de } \\
\text { entidades sin ánimo de } \\
\text { lucro o entidades } \\
\text { externas no } \\
\text { penitenciarias. }\end{array}$ \\
\hline
\end{tabular}




\begin{tabular}{|c|c|c|c|}
\hline $\begin{array}{l}\text { Abierto } \\
\text { (Tercer grado: } \\
165 \text { o segundo } \\
\text { grado artículo } \\
100.2 \text { ) }\end{array}$ & $\begin{array}{l}\text { Unidades } \\
\text { Dependientes }\end{array}$ & $\begin{array}{l}\text { Programas familiares, } \\
\text { formativo-laborales, de } \\
\text { habilidades sociales: } \\
\text { planificación de la vivienda } \\
\text { y tareas, resolución de } \\
\text { conflictos, preparación para } \\
\text { la libertad, prevención de } \\
\text { drogodependencias, } \\
\text { educación infantil (en el caso } \\
\text { de las maternales) etc. }\end{array}$ & $\begin{array}{l}\text { - Educadores/as como } \\
\text { voluntarios o } \\
\text { profesionales de } \\
\text { entidades sin ánimo de } \\
\text { lucro o entidades } \\
\text { externas no } \\
\text { penitenciarias. } \\
\text { - Educadores/as de redes } \\
\text { externas. }\end{array}$ \\
\hline $\begin{array}{l}\text { Abierto } \\
\text { (Medias } \\
\text { alternativas) }\end{array}$ & $\begin{array}{l}\text { Beneficios a la } \\
\text { comunidad }\end{array}$ & $\begin{array}{l}\text { - Programas formativo- } \\
\text { laborales. } \\
\text { - Programas de habilidades } \\
\text { sociales. } \\
\text { - Programas de resolución de } \\
\text { conflictos. }\end{array}$ & $\begin{array}{l}\text { Educadores/as como } \\
\text { voluntarios o } \\
\text { profesionales de } \\
\text { entidades sin ánimo de } \\
\text { lucro o entidades } \\
\text { externas no } \\
\text { penitenciarias. }\end{array}$ \\
\hline
\end{tabular}

A pesar de que la oferta de programas es muy amplia y se desarrollan en los distintos centros penitenciarios, recursos de inserción en semilibertad y en otros centros especializados externos, se hace difícil la extracción de los datos, de los resultados y de los procesos, -y más si queremos específicos-, porque cada centro es quien define sus programas o lo hace en comunión con las entidades colaboradoras ${ }^{10}$.

\section{Consideraciones finales}

Tras el estudio detenido de la temática en torno a la Educación Social Penitenciaria en España, podemos observar una gran evolución en los fundamentos, la norma y la acción, situándose hoy la vertiente educativa en un lugar privilegiado, a pesar de que aún persisten modelos de intervención con mayor peso en las dimensiones punitivas y terapéuticas.

También, por su parte, en los últimos años, la política penitenciaria ha hecho una apuesta por mejorar el marco jurídico, los procesos de intervención, especialmente en colectivos con necesidades (drogodependientes, maltratadas-maltratadores, etc.) e intentan trabajar transversalmente el enfoque de género. Sin embargo, sobre su puesta en marcha y de sus resultados sabemos muy poco.

La literatura especializada y los datos de la realidad encontrados nos evidencian grandes vacíos, tanto en la población, en la estructura del sistema penitenciario, en los modelos teóricos que guían la acción como en las propuestas socioeducativas reales,

${ }^{10}$ Entidad colaboradora: Aquella organización no gubernamental, asociación o fundación que desarrolla programas de intervención en el ámbito penitenciario. 
orientadas hacia la inserción -en todas sus dimensiones- que superen la marginación y exclusión de los/as reclusas/as. También, existe la necesidad de mayor interacción entre la academia y los profesionales y la realidad.

Los enfoques que se proponen en el presente trabajo en torno a la Educación Social Penitenciaria definen un nuevo modelo de pensamiento y acción socioeducativa denominado "Modelo Socioeducativo Emergente" (MSE). Éste se basa en la deconstrucción de procesos, de estructuras, de imaginarios (representaciones sociales) y de situaciones de desigualdad, violencia, vulnerabilidad, marginación o exclusión, a fin de posibilitar el afrontamiento crítico de la vida, adecuar las condiciones y características diferenciales de cada persona presa, integrar la participación en un marco de confianza, el desarrollo de las potencialidades, el consenso, la libertad y la voluntariedad de las personas internadas, el disfrute, la construcción de los propios itinerarios, la concienciación crítica del cambio, etc. Permite generar programas y acciones integrales que buscan superar los efectos de la prisionalización, potenciar la autonomía, la emancipación, la autogestión, la libertad y el empoderamiento (personal, familiar y social).

No tener en cuenta estos planteamientos, que consideramos básicos, en las acciones llamadas socioeducativas es arriesgarse a la ineficacia y al vaciamiento de la propia palabra educación. Freire (1997) habló de esta posibilidad y la denominó 'educación bancaria', donde el sujeto es convertido en objeto por parte de los 'educadores'. Núñez (1989) afirma a propósito de esta cuestión, y como un problema que se presenta al/la educador/a, que la persona inadaptada se caracteriza por una escasa disponibilidad o interés hacia el trabajo educativo y por un escaso ejercicio de sus responsabilidades. Consecuentemente emerge el reto de buscar su voluntariedad, la motivación y el disfrute participativo.

Por otro, se erige imprescindible el acompañamiento, asesoramiento y continuidad en el proceso de reconstrucción multidimensional de sus vidas y de los efectos de la privación de libertad y de la exclusión, con mayor énfasis, durante la transición y hasta la recuperación de la autonomía. Todo ello incidirá en la prevención de las recaídas -sí son adictos/as- y las reincidencias delictivas, pero sobre todo ofrecen un horizonte donde pueden ser capaces de retomar o convertirse en miembros activos de la sociedad y sujetos de derechos y responsabilidades. A pesar de los avances y esfuerzos quedan muchos desafíos, tanto para la sociedad, para la Educación Social como para la Institución Penitenciaria, especialmente queda por abordar el principio básico de la libertad y la liberación, revolución que el Modelo Socioeducativo Emergente (MSE) plantea.

\section{Referencias bibliográficas}

ADHEX (2011). El trabajo de Adhex en la prisión. Adhex prisiones. En: $\mathrm{http}: / /$ centroderechoshumanos.com/areas-de-trabajo/reclusos/. Consultado el 4 de Enero de 2012.

ALMEDA, E. (2010). Privación de libertad y mujeres extranjeras. Viejos prejuicios y 
nuevas desigualdades. En Fanny T. Añaños (coord.). Las mujeres en las prisiones. La educación Social en contextos de riesgo y conflicto. Barcelona: Gedisa, p.p.201-234.

ANDREWS, D. A., y BONTA, J. (2006). The psychology of criminal conduct (4a. ed.). Cincinnati, OH: Anderson Publishing Co.

AÑAÑOS, F. (2012). Violencias y exclusiones. Enfoque socio-educativo y de la paz. Convergencia. Revista de Ciencias Sociales, 59, mayo-agosto 2012 (En prensa).

AÑAÑOS, F. (Coord.) (2010). Mujeres presas y su relación con las drogas. Implicaciones desde la Educación Social. En Fanny T. Añaños (coord.). Las mujeres en las prisiones. La educación Social en contextos de riesgo y conflicto. Barcelona: Gedisa, p.p.77-100.

AÑAÑOS, F. y DEL POZO, F.J. (2010). Pedagogía del arte en las prisiones españolas: El caso del C.P. de Albolote (Granada) "Seminario Europeo Mutations des sensibilités en Europe aujourd'hui et au colloque -Lárt de prendre soin" Centro de Estudios de las Artes Contemporáneas. Université Lille 3. Marzo 2010. Lille. Ponencia sin publicar.

AYUSO, A. (2000). La intervención socioeducativa en el tratamiento penitenciario. Pedagogía Social. Revista Interuniversitaria, 6/7,p.p. 73-99.

AYUSO, A. (2003). Visión crítica de la reeducación penitenciaria en España. Valencia: Nau Llibres.

BANDURA, A. (1997). Teoría del Aprendizaje social. New Jersey: Englewood cliffs.

BOWLBY J. (1995). Maternal Care and Mental Health. The master work series (2 ${ }^{\mathrm{a}}$ ed.). Northvale, NJ. London: Jason Aronson.

BLOOM, M. (1998). Preventing Juvenile Delinquency and Promoting Juvenile Rightency. En Delinquent Violent Youth. Theory and Interventions (edit. Gullotta, Adams y Montemayor), Advances in Adolescent Development, Vol. 9. Thousand Oaks: Sage Publications. CA, p.p.256-308.

CARIDE, J.A. (2010). La Educación Social como práctica de y hacia la libertad en contextos penitenciarios. En Fanny T. Añaños (coord.), Las mujeres en las prisiones. La educación Social en contextos de riesgo y conflicto. Barcelona: Gedisa, pp. 45-64.

CLOWARD, R.A. y OHLIN, LL.E. (1960). Delinquency and opportunity: A theory delinquents gangs. New York: Free Press.

DE LA CUESTA, J.L. (1993). La resocialización: objetivo de la intervención penitenciaria. Papers d'estudis i formació, 12, diciembre 1993,p.p. 9-21.

DEL POZO, F.J. y MAVROU, I. (2010). Experiencias y Programas Socioeducativos en el Medio Penitenciario cerrado y abierto con Mujeres e Infancia. En Fanny Añaños (coord.). Las mujeres en las prisiones. Educación social en contextos de riesgo y de conflicto. Barcelona: Gedisa, pp.235-260.

DEL POZO, F.J. (2008a.). Las Unidades dependientes de madres reclusas: una 
propuestas socioeducativa de desarrollo comunitario. Sociedad educadora, sociedad lectora XXII Seminario Interuniversitario de Pedagogía social. Cuenca: CEPLI. Universidad de Castilla la Mancha. p.103.

DEL POZO, F.J. (2008b.). Los programas individualizados socioeducativos de tratamiento en las Unidades dependientes de madres. En: F. Añaños Bedriñana, F.J. Del Pozo Serrano, F.J. e I. Mavrou (Coords.). Educación Social en el Ámbito Penitenciario: Mujeres, Infancia y Familia. Nativola: Granada. p.p.488-503.

DEL POZO, F.J. (2010). La evolución histórica y proyección de los contextos penitenciarios materno-filiares como espacios socioeducativos. En: Del Pozo Serrano, F, Añaños, F; Mavrou, I; Sevilla, D (Coords.). Educación, Salud y Drogodependencias: Enfoques, programas y experiencias en ámbitos de exclusión. Drugfarma: Madrid. p.p.245-260.

DEL POZO. F.J. (2011). La metamorfosis de lo creado: participación del arte y la cultura como herramientas de empoderamiento. En Jiménez, M.; Robles Sanjuán, V.; Añaños Bedriñana F.; y Del Pozo F.J. (Coords.). Educación para la Igualdad: Reflexiones y Propuestas. Natívola: Granada. p.p. 66-88.

EYSENCK, S. B. G. y EYSENCK, H. J. (1971). A comparative study of criminals and matched controls on three dimensions of personality. British Journal of Social and Clinical Psychology, 10, p.p.362-366.

FERMOSO, P. (2003). ¿Pedagogía social o ciencia de la Educación social? Pedagogía Social. Revista Interuniversitaria, 10, p.p.61-86.

FRANCH, J. y MARTINELL, A. (1994). Animar un proyecto de educación social. La intervención en el tiempo libre. Barcelona: Paidós.

FREIRE, P. (1997). Educaçâo no cidade, Sâo Paulo, Cortez, 1991 [La educación en la ciudad. México, D.F.: Siglo XXI, 1997].

FREUD S. (1906). El psicoanálisis y el diagnóstico de los hechos en los procedimientos judiciales. En: S. Freud. Obras completas. Tomo II. Madrid: Ed. Biblioteca Nueva.

GARCÍA, J. y SANCHA, V. (1985). Psicología Penitenciaria. Madrid: Centro de Publicaciones de la Universidad Nacional de Educación a Distancia.

GARRIDO, V. y GÓMEZ A.M. (1995). La Educación Social en el ámbito penitenciario. Comunicación, Lenguaje y Educación, 27, p.p.53-60.

GARRIDO, V. y GÓMEZ A.M. (1996). El Modelo cognitivo aplicado a delincuentes institucionales. El programa de pensamiento prosocial. Revista Complutense de Educación, 7 (2), p.p.137-156.

GIL, F. (2010). La acción pedagógica en las prisiones. Posibilidades y Límites. Revista Española de Pedagogía, 245, enero-abril 2010. En: http://revistadepedagogia.org/ 20100121396/vol.-lxviii-2010/n\%C2\%BA-245-enero-abril-2010/la-accionpedagogica-en-las-prisiones.-posibilidades-y-limites.html ; Consultado el 2 de Febrero de 2012. 
GOLEMAN, D. (1996). Inteligencia emocional. Barcelona: Kairós.

GLASER, R. (1984). Education and thinking: The role of knowledge. American Psychologist, 13, p.p.145-182.

I.E. INTERNACIONAL DE LA EDUCACIÓN (2007). Resolución sobre la educación en los establecimientos Penitenciarios. Berlin: Education International.

II.PP. (2011). Módulos de respeto. En: http://www.institucionpenitenciaria.es/web/portal/ Reeducacion/ProgramasEspecificos/modulosRespeto. Consultado el 3 de Febrero de 2012.

II.PP. (2012). Reeducación y Reinserción Social. Instituciones Penitenciarias. En: http://www.institucionpenitenciaria.es/opencms/opencms/Reeducacion. Consultado el 16 de Febrero de 2012.

JULIANO, D. (2010). La criminalización de las mujeres. Estigmatización de las estrategias femeninas para no delinquir. En Fanny T. Añaños (coord.), Las mujeres en las prisiones. La educación Social en contextos de riesgo y conflicto. Barcelona: Gedisa, p.p. 25-44.

HAMM, M. S. y SCHRINK, J. L. (1989). The conditions of effective implementation: A guide to accomplishing rehabilitative objectives in corrections. Criminal Justice and Behavior, 16, p.p.166-182.

HATHAWAY, S. R. y E. D. MONACHESI. (1953). Analyzing and predicting juvenile delinquency University of Minnesota Press: Minneapolis. Minnesota.

LEMERT, E. (1972). Human Deviance, Social Problems, and Social Control. Nueva Jersey: Prentice-Hall.

MARTÍN, V. M. (2010). Educación Social y procesos de empoderamiento como ejes de intervención en la institución penitenciaria. En Francisco Del Pozo, Fanny Añaños, Josefina Mavrou y Diego Sevilla (Coords.), Educación, Salud, y Drogodependencias. Enfoques, programas y experiencias en ámbitos de exclusión. Madrid: Multimedia, S.L., p.p.68-82.

MAYOR, F. (2000). Un mundo nuevo. Barcelona: Ediciones UNESCO-Círculo de Lectores.

MELENDRO, M. (2010). Enfoque en los programas; resiliencia y sinergias en la intervención. En: F. Añaños. Proyecto de investigación: "mujeres reclusas drogodependientes y su reinserción social. Estudio socioeducativo y propuestas de acción". Inédito.

MILAN M. y EVANS J. (1987). Intervention with incarcerated offerders. En I. Weiner y A. Hess (Eds.). Handbook of forensy psycolochy, p.p. 553- 583. New York: Wiley.

MORATA, M.J.; MURO, P. y PALASÍ, LUNA, E. (2011). La pedagogía comunitaria en centros penitenciarios. II Jornada Monográfica de la Sociedad Iberoamericana de Pedagogía Social. Pedagogía Social y Educación Social. Una mirada al futuro. SIPS: Madrid. 
MORRIS, E. K. y BRAUKMANN, C. J. (1987). The dimensions of applied behavior analysis for crime and delinquency. En: E. K. Morris y C. J. Braukmann (Eds.). Behavioral Approaches to Crime and Delinquency. Nueva York: Plenum Press.p.p.27-59.

NÚÑEZ, V. (1989). El Educador especializado como antecedente histórico del Educador social. Revista Menores,p.p.13-38.

NÚÑEZ, V. (2010). Espacio carcelario/espacios educativos. En Fanny T. Añaños (coord.), Las mujeres en las prisiones. La educación Social en contextos de riesgo y conflicto. Barcelona: Gedisa, p.p.65-75.

ORTE, C. (2008). La intervención familiar con mujeres drogodependientes y con procesos legales. En: F. Añaños, F. J., Del Pozo, e I. Mavrou, (Coords.). Educación Social en el Ámbito Penitenciario: Mujeres, Infancia y Familia. Granada: Natívola. p.p. $248-260$.

ORTEGA, J. (coord.) (1999). Pedagogía social especializada. Pedagogía de menores en dificultad y en conflicto social. Barcelona: Ariel.

PANTOJA. L. (2010). Actuación socioeducativa con mujeres presas: el papel de los educadores social. En Fanny T. Añaños (coord.), Las mujeres en las prisiones. La educación Social en contextos de riesgo y conflicto. Barcelona: Gedisa, p.p. 101-122.

PANTOJA VARGAS, L. y AÑÃOS-BEDRIÑANA, F. (2010). Actuaciones socioeducativas con menores vulnerables, en riesgo, relacionados con las drogas. Reflexiones críticas. Pedagogía Social. Revista Interuniversitaria, 17, p.p.109-122.

PÉREZ, G. (2005). Educación Social. Revista de Educación, 336,p.p. 7-18.

REDONDO, S. (1995). Evaluación y tratamiento en prisiones. En Clemente M. (Coord.), Fundamentos de la Psicología jurídica, 18. Madrid: Pirámide. p.p.339-353.

SÁEZ, J. (2010). ¿Existe una educación específica para las mujeres en las prisiones? Algunas reflexiones desde la lógica profesional. En Fanny T. Añaños (coord.), Las mujeres en las prisiones. La educación Social en contextos de riesgo y conflicto. Barcelona: Gedisa, p.p.101-122.

SCARFÓ, F. (2002). El derecho a la educación en las cárceles como garantía de la Educación en Derechos Humanos. Revista IIDH-Instituto Interamericano de Derechos Humanos, 36, p.p.291-324.

SECRETARÍA GENERAL DE INSTITUCIONES PENITENCIARIAS (2012). Estadística mensual de Población Reclusa. Febrero, 2012. En: http://www.institucionpenitenciaria.es/opencms/opencms/administracionPenitenciaria /estadisticas.html.

TAYLOR, I., WALTON, P., YOUNG, J. (2000). La nueva criminología. Buenos Aires: Amorrortu Editores.

VYGOTSKI, L.S. (1978). Mind in society: The development of higher psychological processes. Cambridge, Massachussetts: Harvard University Press. 
WILKINS, L.T. (1965). Social deviance: Social, policy, action and research. Tavistock: American Ed. Englewood Cliffs. N. J. Prentice Hall. Londres.

YAGÜE, C. (2008). Mujeres y madres en prisión. Intervención basada en necesidades y demandas. En: F. Añaños, F. J., Del Pozo, e I. Mavrou, (Coords.). Educación Social en el Ámbito Penitenciario: Mujeres, Infancia y Familia Granada: Natívola. p.p. 311322.

YAGÜE, C. (2010). Panorama actual de la situación de las mujeres y madres en los centros penitenciarios españoles. El programa de igualdad. En Fanny T. Añaños (coord.), Las mujeres en las prisiones. La educación Social en contextos de riesgo y conflicto. Barcelona: Gedisa, p.p.183-200.

YAGÜE, C. (2011). Proyecto de Mediación familiar entre mujeres internas e Instituciones Penitenciarias y sus familias. Instituciones Penitenciarias. En: http://www.institucionpenitenciaria.es/web/export/sites/default/datos/descargables/no ticias/Intervencion_ConchaYague_ProgramaMediacionFamiliar.doc.pdf. p.p. 1-4.

YELA M. (2004). La Exclusión social. Teoría y práctica de la intervención. En: Rubio M.J. y Monteros (Coords.). Breve reseña Teórico- histórica de la Institución penitenciaria, Madrid: CCS. p.p.313-330.

\section{Correspondencia con los autores}

Francisco José DEL POZO SERRANO

Dpto. Teoría e Historia de la Educación y Educador social.

Universidad Complutense de Madrid.

Dirección: C/Rector Royo Villanova s/nº 28040 . Madrid.

Correo-e: f.delpozo@pdi.ucm.es

Fanny T. AÑAÑOS-BEDRIÑANA

Facultad de Ciencias de la Educación. Universidad de Granada

Campus Cartuja s/n, 18071, Granada

Correo-e: fanntab@ugr.es 